\title{
CONTRIBUTORY ROLE OF VIRTUAL COURSES VIA SKYPE TO CONTROL EMBARRASSMENT OF IRANIAN EFL LEARNERS' PERFORMANCE
}

\author{
Elham JAHANBAKHSH \\ English Department, Islamic Azad University \\ Isfahan Branch, Isfahan, Iran \\ Dr. Azizeh CHALAK \\ English Department, Islamic Azad University \\ Isfahan Branch, Isfahan, Iran
}

\begin{abstract}
In recent years, there has been an increasing interest in integration of technology for pedagogical purposes. The present study aimed at finding out how presentation in the frame of virtual courses can control embarrassment and shyness of Iranian EFL learners. The practical part concentrated on using Skype for the purpose of presentation in seminar courses. The data collection was based on Revised Cheek and Briggs Shyness Scale (PRSS 14 item) and the target group was selected from three seminar classes during 2016. The final scores of the face to face presentation were compared with presentations via the Skype in such courses. The data were analyzed using a paired sample t-test. The results revealed a significant difference between observed results and expected results. The data were also gathered from semi-structured interviews based on the students' attitudes towards using the Skype to increase the validity of the method. The findings showed that the students had highly positive attitudes towards integration of the technology. This study could impact those students who have enough competence but their personality type prevents them from transferring their knowledge. It could also be fruitful for curriculum developers who want to organize pedagogical area efficiently by overcoming time and place constraints.
\end{abstract}

Keywords: Embarrassment, performance, Skype, virtual, virtual courses.

\section{INTRODUCTION}

The Internet and its applications play a vital role in our life, so the advantages of them and somehow replacement of them with some traditional way should be noticed. These days, many classes are presented virtually because of time and place constraints. In future students might even do not meet a lecturer face-to-face in a classroom.

The relationship between technology and EFL learning is a significant area to do research studies and because of students' familiarity with technology devices in everyday life and their improved computer literacy, it is demanding to use technology more effectively. As Chirimbu and Tafazoli (2013) believe, for many language learners around the world, new digital environments create a useful way for learning language and also the main medium in which they will actually use their second language in ever day life. Almost all university students are equipped with functionalities and application on their cell phones, so using these applications 
to facilitate language learning and communicate with each other is so widespread. Bicknell (1999) stated that using the Internet and its applications act as a motivational apparatus which gives students the chance to use all four language skills. In another study, Asoodar, Marandi, Atai, and Vaezi (2014) put forth on that students in the virtual class proved significantly more enthusiastic about collaborative work compared to students in the blended class. Working together as a team is a subject matter of many research studies and it can be more possible through the Internet via these new technology tools. In some studies, it is named virtual team. A virtual team is a collection of a small number of interdependent, geographically dispersed, individuals that have a common goal and depend on electronic linking in order to collaborate and achieve it.

Education is a process in which the establishment of a defined communication between the teacher and the learner leads to the promotion of knowledge, increase of information, acquisition of skill, and generally, to the making of changes in a fixed ratio in learners' mental and practical capabilities. Based on this, as cited in Fooladvand and Yarmohammadian (2011), it should be mentioned that education is divided into two forms: traditional and virtual. Traditional education refers to that group of teachings the basic portion of whose order is based on the teaching system. In another word, in traditional education, the learner is obliged to harmonize his own techniques and learn ability with the types, techniques, skills and desires of the teacher. On the contrary, virtual education discussed under titles such as electric education, internet education, computer based and "web" based education and finally, virtual education, refers to the group of teaching the basic portion of whose system is founded on the network based learning system in which the learner is the major axis (Dilamaghani, 2001).

Nowadays, methods and approaches of virtual education are increasingly used at universities and technology and tools are used more and more in education and learning environments. As Bonk (2011) claims, anyone can now learn anything from anyone at any time.

One application of virtual courses is the employment of this system at universities. A virtual university has been founded to be free of traditional systems' limitations and characteristics. Traditional universities should inevitably comply with the course of new changes. In the new environment, the role of instructors and trainers will change. They will more play the role of a facilitator and trainer or of educational designers. In process of dealing with virtual courses and the role of teachers Atai and Dashtestani (2013) claim that online classes should be treated differently. In online courses, teachers may not be able to explain instructions, perceive and mentor the learners as typically practiced in face-to-face classrooms. Therefore, it may be argued that initiation and facilitation of discussions, as well as providing feedback require different approaches.

Skype is an excellent tool for ESL/EFL educators who are tentative about using more sophisticated learning technologies. Because Skype originally began as a Voice Over Internet Protocol (VOIP) service, as a cost-effective alternative to traditional phone calls, its application as a personal communication tool makes it more attractive to those who struggle to incorporate technology into their classrooms. In the ESL/EFL classroom, Skype can be used to provide a variety of authentic learning experiences to students, including an interview with an author or other native English speaker, or an international collaborative project with other classrooms. Skype can be used to create and maintain relationships with prospective students. This may be of particular relevance for programs that recruit international students. One example is to have a Skype account that students can call to ask questions. These calls can be answered by ESL/EFL school staff, just as the phone is. It is this feature that makes Skype a potential tool for language teaching and learning. According to Elia (2006), Skype facilitates language tandem exchange in which "two people of different mother tongues collaborate in the learning of each other's language" (p. 271). 
Embarrassment is usually categorized as a 'self-conscious' emotion (Fischer \& Tangney, 1995). Other self-conscious emotions include guilt, shame, pride and hubris (Tracy \& Robins, 2003). They are called 'self-conscious' emotions because self-focused attention appears to be a necessary condition for the experience.

According to psychological point of view, there is no problem for some students to present their lecture and have a face to face presentation but for others with fragile personality and suffering from their embarrassment; it is such a big deal, so embarrassment negatively affects communication and contact with others (Philip, 1991).

Learning a language is what needs practice. In some countries English is a foreign language such as Iran and students have no chance to practice it in outside atmosphere unless in the classroom. Social contact and have a face to face communication is something that students feel lack of it in Iran so distance learning and virtual courses are excellent methods for those who want to overcome their embarrassment step by step.

Some studies have shown that embarrassment influences the communication strategies learners employ in a language class. For instance, Ely (1986) offers that embarrassed learners were less likely to take risks in the language class. Similarly, Steinberg and Horwitz (1986) found that compared to learners who have no problem with communicating face to face, anxious learners and those who are suffering from embarrassment paid more attention to accuracy and correct messages rather than fluency and interpretive messages.

Students who are studying EFL in higher level of education have enough competence, but some of them cannot transfer their knowledge in public and it is something that they usually suffer from it. Brown (2007) stated that social contact in interactive language is not what the speakers say; but how they say it, what they convey with body language, gestures, eye contact, physical distance and other nonverbal messages. In addition to use of language in social interactions, paralinguistic elements of speech such as pitch, stress, and intonation are important in effective oral communication (Richards \& Renandya, 2002). To this end, the present study aimed to find out how presentation in virtual condition via Skype can control embarrassment and shyness of Iranian EFL learners. In order to achieve the objectives of the study, this study addressed the following research questions:

$>$ Is there any significant difference between the speaking performance of Iranian EFL learners in traditional seminar courses and their performance in the form of virtual course via the Skype?

$>$ Does performing in the virtual condition via Skype play any roles to control embarrassment of Iranian EFL learners?

$>$ What are students' attitudes and opinions about performing courses via the Internet through the Skype?

\section{METHODOLOGY}

\section{Participants and Setting}

This study was done at Islamic Azad University, Isfahan (Khorasgan Branch) (IAUIB), in Iran during 2016. The students studying in higher level of education in EFL major were the participants of this research study. Three classes were presented seminar course on the second semester of that academic year. The students in the seminar classes were selected to serve the purpose of this research study. All of the classes at IAUIB are equipped with essential services which is vital for this stage of study. The students offer their presentations via the data show and they can bring their laptop computers or their flash memories to the classroom. The participants of the study were $\mathbf{3 5}$ students out of $\mathbf{5 0}$ and the target population 
was selected through psychological test to determine their personality type. They were male and female with different ages and all of them were studying at MA level in EFL majors.

A mixed-method approach was adopted in this research study. Quantitative part of it consisted of gathering the data through the routine way of presenting lecture which means to apply for presentation in the classroom and students' lecture or performance was checked through Conversational Skills Rating Scale (CSRS). The score of students gathered and compared with face-to-face presentation via Skype in order to find out the effectiveness of it. In qualitative part a psychological questionnaire was given to students in order to obtain the target group of this research study and to increase the confidence in the research data, face-to-face unstructured interviews was made. So, the design of this study was an experimental paradigm to compare scores in pre/post-tests, but one group served the purpose of the study in both face to face and via Skype presentation to examine the impact of the treatment.

\section{Instruments}

A range of the quantitative and qualitative instruments were employed in this research to collect data. A psychological questionnaire consisting of fourteen questions, known as CheekBriggs Shyness Scale (1990), as a reliable and valid questionnaire was employed to choose the target population of this study. The required software to perform the study was Skype which was a free application. It was recommended to the students to utilize headphones to prevent distraction. Skype allows video-conferencing and performing via the Internet in the form of virtual course. The subjects were asked to record part of their presentation in order to be checked. In quantitative part of the study, the scores of the subjects in presenting face to face and through online program were gathered and checked. Interviews were made with some of the subjects voluntarily to increase the confidence in the research data.

\section{Data Collection Procedure}

The psychological questionnaire, which focused on the subjects' embarrassment and shyness, was administered to three seminar courses at Islamic Azad University, Isfahan (Khorasgan Branch) for MA students. Regarding each student's answer to the Cheek-Briggs questionnaire (1990), the score of them were calculated and the target population of the study was determined. The participants completed the 14-item version of the (PRSS).

Each participant was allocated a time to perform their presentation face to face in the classroom, after that a short discussion was done according to the subject of the lecture. In this research study, the researcher observed each participant's presentation and the professor of the course scored the participants according to conversational skills rating scale (CSRS) as it was mentioned. A day before their presentations in routine way which was face to face and in the classroom in front of their classmate and professor, they were asked to present their lecture via Skype software at home and in the form of a virtual session. The thing that was considered during this research study was to notify the participants who were on the call that the researcher was recording part of their presentation so ethical issue was observed in this research study. All of the participants were equipped with the software and they were eager to present their lecture in the form of virtual course but the target group was selected through the psychological questionnaire and their lecture was compared in the two form of presentation. Also, the students' presentations were checked according to conversational skills rating scale in both cases, which was face to face and via Skype in the form of virtual courses.

Data Analysis Procedure

After collecting the data through the questionnaires, they were statistically analyzed using the Statistical Package for Social Science (SPSS) in order to find the target group of this research study. Also the scores of the participants through face-to-face presentation and via 
Skype were collected. Paired sample $t$ test used to analyze the data to see if there was a significant difference in both forms of presentation. The analysis of the interview transcripts following a categorization item model completed the procedure of data collection and highlighted the results of the study.

\section{RESULTS}

\section{Results of the Psychological Questionnaire}

In this study, the Revised Cheek and Briggs Shyness Scale (PRSS 14-item) in Iran, retaining its original statement-format, was prepared. Of the 14 items, items 6, 9, and 12 were reversely keyed. The participants completed the 14-item version of the PRSS (14). The participants were requested to respond to each item on a 5-point scale. They were asked to read each item carefully and decide to what extent it is characteristic of their feelings and behavior, and to fill in the blank next to each item by choosing a number from the scale printed below. The ten items $(1,2,3,4,5,7,8,10,11,13$, and 14) of the shyness subscale of the PRSS were assigned to the first factor, and one factor corresponding to the four items where the responses are reversely coded (items $6,9,12$ ).

Examined participants gave their answers on a 5-point continuum, ranging from 1 (Strongly disagree) to 5 (Strongly agree). A five-point Likert scale was used; scores range from 14 to 70 with higher scores reflecting greater shyness and embarrassment. The highest result amounts to 45 and it was the average shyness level.

In this research study, the scores upper than 45 allocated as embarrassment participants and lower than this score was shown that the participants did not have any problems in communicating in public and presenting their lecture in seminar courses and actually they could not take in the category of embarrassment subjects. The Cheek-Briggs questionnaire (1990) was distributes among 50 students who took seminar courses in the second semester of 2015-2016. The participants' responses to the psychological questionnaire were analyzed with SPSS 19 in terms of frequencies and percentages. The results showed that among all of the participants (50) in this study, about $70 \%$ of the subjects were suffering from embarrassment. It was also revealed that 15 participants of this research study had no problem in this case. Table 1 summarizes these results.

Table 1. Descriptive Analysis of Psychological Questionnaire

\begin{tabular}{|c|c|c|c|c|c|c|}
\hline \multicolumn{7}{|c|}{ Results of Cheek Briggs Shyness Questionnaire } \\
\hline \multirow{2}{*}{$\begin{array}{l}\text { Domains } \\
\text { Domain } 1\end{array}$} & \multirow[t]{2}{*}{ Questions } & \multirow[t]{2}{*}{$\begin{array}{l}\text { No. of } \\
\text { Questions }\end{array}$} & \multicolumn{2}{|c|}{ Embarrassment } & \multicolumn{2}{|c|}{ W/Embarrassment } \\
\hline & & & $\mathbf{F}$ & $\mathbf{P}$ & $\mathbf{F}$ & $\mathbf{P}$ \\
\hline $\begin{array}{l}\text { No Self } \\
\text { Confidence }\end{array}$ & $3,10,11,13$ & 4 & 12 & 0.24 & 4 & 0.08 \\
\hline \multicolumn{7}{|l|}{ Domain 2} \\
\hline Social Anxiety & $1,2,4,5,7,8,14$ & 7 & 9 & 0.18 & 6 & 0.12 \\
\hline \multicolumn{7}{|l|}{ Domain 3} \\
\hline $\begin{array}{l}\text { Embarrassment } \\
\text { with Strangers }\end{array}$ & $6,9,123$ & 3 & 14 & 0.28 & 5 & 0.1 \\
\hline Total & & 14 & 35 & 0.7 & 15 & 0.3 \\
\hline
\end{tabular}


Results of the Comparison between Face to Face and via Skype Presentations

When the participants of the study were characterized by the Cheek-Briggs psychological questionnaire (1990), the following procedure of this research study was done by the target group of population. During the semester, the students were allocated a time to present their lecture or presentation, which was an article or part of a thesis, face to face in front of their classmate and instructor of the course. The instructor assigned their scores according to Conversational Skills Rating Scale (CSRS).

A day before their presentation in its routine way, to prevent time interval, they were asked to present their lecture that they have already presented in the class via Skype in the form of virtual courses and again the instructor scored them. For each one of the subjects, two series of scores was dedicated and they were compared with statistical technique and paired sample t test.

The scores of 35 participants in two forms of presentation were analyzed to examine whether the difference between results were significant. The results are shown in the following tables. Table 2 and 3 show descriptive statistics and correlations between two forms of presentations, face to face and via Skype.

Table 2. Descriptive Statistics of Two Forms of the Presentation

\begin{tabular}{cccccc}
\hline \multicolumn{7}{c}{ Paired Samples Statistics } \\
\hline & Mean & N & Std. Deviation & Std. Error Mean \\
\hline \multirow{2}{*}{ Pair 1} & Face to Face Presentation & 17.17 & 35 & 1.021 & 0.17 \\
\cline { 2 - 6 } & Via Skype Presentation & 17.84 & 35 & 0.91 & 0.15 \\
\hline
\end{tabular}

Table 3. Correlation between Two Forms of Presentation

\begin{tabular}{lllll}
\hline \multicolumn{1}{l}{ Paired Samples Correlations } & & & \\
\hline & N & Correlation & Sig. \\
\hline Pair 1 & Face to Face \& Skype & 35 & 0.71 & .000
\end{tabular}

As Table 3 indicates, the significance between the two forms of presentations, face to face and via Skype, was less than 0.05 , showing that there was a significant difference between two ways of presentation.

Table 4 illustrates the results of paired sample test in order to determine the difference between the presentations in routine way which was face to face and the suggestion in this research study which was via Skype in the form of virtual courses. 
Table 4. Paired Sample Test

\begin{tabular}{|c|c|c|c|c|c|c|c|c|c|}
\hline \multicolumn{10}{|c|}{ Paired Samples Test } \\
\hline & & \multicolumn{5}{|c|}{ Paired Differences } & \multirow{3}{*}{$\mathbf{t}$} & \multirow{3}{*}{ df } & \multirow{3}{*}{$\begin{array}{l}\text { Sig. } \\
\text { (2-tailed) }\end{array}$} \\
\hline & & \multirow[t]{2}{*}{ Mean } & \multirow[t]{2}{*}{$\begin{array}{l}\text { Std. } \\
\text { Deviation }\end{array}$} & \multirow[t]{2}{*}{$\begin{array}{l}\text { Std. } \\
\text { Error } \\
\text { Mean }\end{array}$} & \multicolumn{2}{|c|}{$\begin{array}{l}95 \% \text { Confidence } \\
\text { Interval of the } \\
\text { Difference }\end{array}$} & & & \\
\hline & & & & & Lower & Upper & & & \\
\hline \multirow[t]{2}{*}{ Pair1 } & $\begin{array}{l}\text { Face to } \\
\text { Face }\end{array}$ & -0.67 & 0.73 & 0.12 & -0.92 & -0.41 & -5.38 & 34 & .000 \\
\hline & Skype & & & & & & & & \\
\hline
\end{tabular}

The results revealed that both upper and lower differences were negative, so the mean of the two ways of the presentations were lower than zero and the subjects of the study scored significantly greater on the presentations via Skype so the mean score of face to face presentations was lower than the presentations via Skype

\section{Results of the Observation}

Observation was used in this study to increase the validity of the method. It helped the researchers to see the changes over time. The observations were carried out while the participants of the study were busy with their presentations. During the repeated class observations, it was found that the subjects were satisfied to have the opportunity to present their lecture via Skype in the form of virtual course. Based on the observations, almost all of the subjects were really participated in the project. However, there were limited participants who did not take part in the activity (5 out of 35 ). The results obtained from observation showed that the participants were eager to overcome their embarrassment as future teachers and they were looking for a way to have this opportunity in order to solve the problems of presenting their seminar courses in a usual and routine way.

\section{Results of the Interview}

At the end of the project, a semi-structured interview including 10 questions was conducted in order to elicit information from the participants. Fifteen students voluntarily took part in this phase of the study. The subjects' points of view about the project, the usefulness and uselessness of presentations via Skype in the form of virtual courses, and their attitudes toward the project were checked. Table 5 show the frequency and percentage of the subjects' answers to the questions of the interview.

Table 5. Results of the Interview with the Subjects

\begin{tabular}{lllll}
\hline Questions & Domains & F & P \\
\hline $1-3$ & $\begin{array}{l}\text { Usefulness of Virtual Courses to Control } \\
\text { Embarrassment }\end{array}$ & 12 & 80 \\
4 & Time and Place Saving & 15 & 100 \\
5 & Ease to Work with Skype & 12 & 80 \\
$6-7$ & Administration of Project in Educational system & 12 & 80 \\
8 & Face with any Problems during the Presentation & 7 & 47 \\
9 & Observation of any Useless Point & 3 & 20 \\
10 & Enjoyment the Experience & 14 & 93 \\
\hline
\end{tabular}

$\mathbf{N}=\mathbf{1 5}$ 
As it can be seen in Table 5, in most of the questions more than $75 \%$ of the participants had a good sense of the project and generally their experience. Those students who faced with problems during their presentation complained about the speed of the Internet and no good equipment in Iran. The participants were so eager to have the virtual courses in educational system and $80 \%$ of them answered positively to apply the virtual courses in the educational system especially in higher level of education. The following figure indicated the summary of the interview in the form of columns.

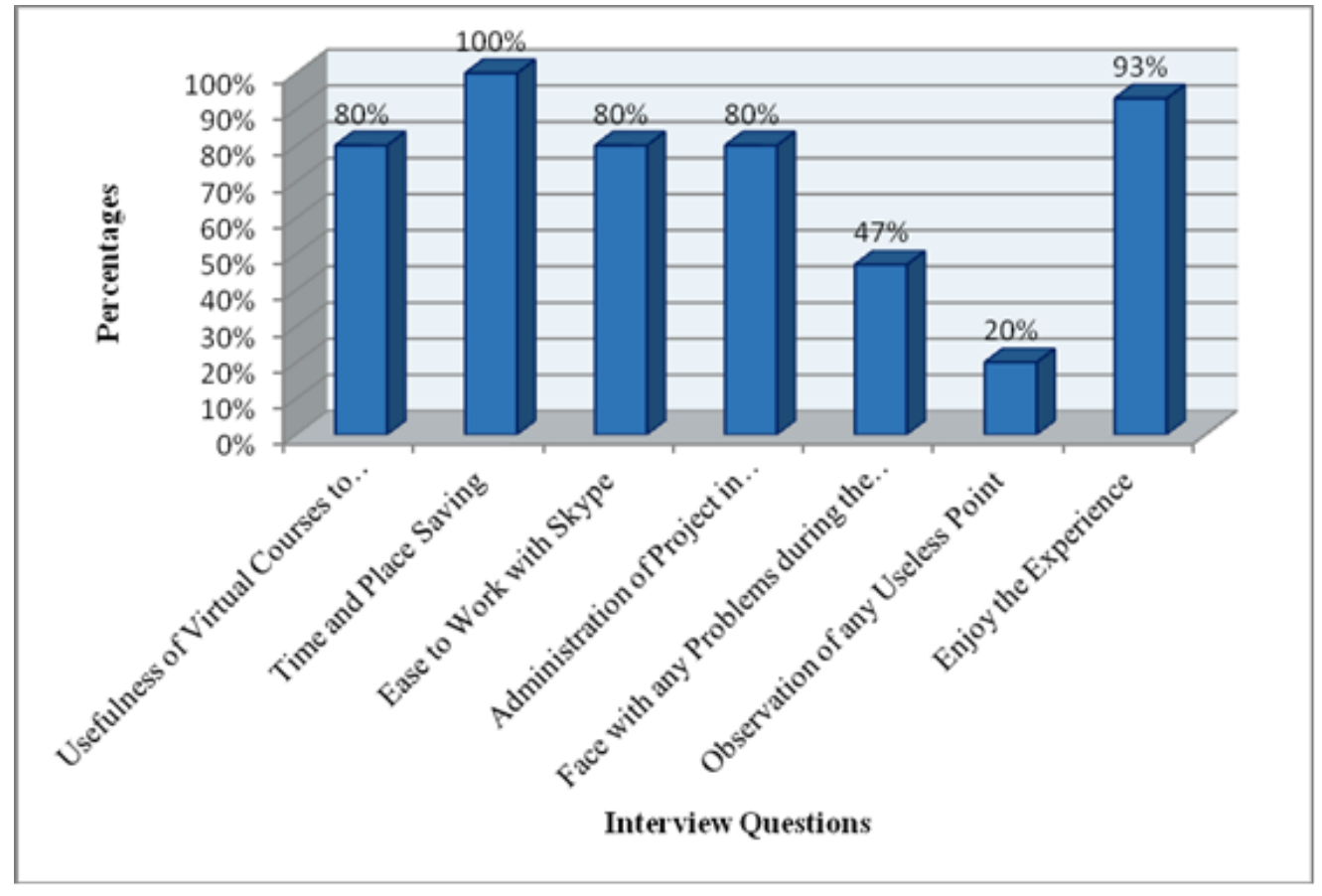

Figure 1. Results of the interview with the subjects.

\section{DISCUSSION}

As many language learners identify communication ability as one of the primary goals for studying a particular language and also it is one of the most difficult for studying Foreign/Second language (FL/SL). The aim of this study was to employ the Internet tools for communication purposes and solve the problems of it. The result is in line with the findings of Levy (2009) that technology tools should be employed especially to develop the difficult oral language skills-speaking and listening.

Presentations of the participants in face to face and via Skype in the form of virtual courses were compared on the second phase of data collection. The results demonstrated that there is a significant difference between qualities of the participants' lecture in face to face and via Skype presentation. In the interview section, they confirmed that presentation via the Skype could control their embarrassment and anxiety. In speaking and giving presentation in public, embarrassment could affect the quality of the presentation, prevent having eye contact with audiences and other feature of being a good and effective speaker.

As Brown (2007) stated, the social contact in interactive language is not what the speakers say; but how they say it, what they convey with body language, gestures, eye contact, physical distance and other nonverbal messages are important in giving presentation. Control and overcome the embarrassment step by step for communication and speak in public was the aim 
of this research study. Communication tools such as Skype play an important role to control the embarrassment that EFL learners have at the beginning of teaching experience.

The results of the interview revealed that $80 \%$ of the subjects found performing through the Internet useful experience and more than $90 \%$ of them expressed that working through the Internet via Skype was an enjoyable activity. During the direct observation, the researcher found that the participants were motivated to present their lecture in the new way. The result of the study are in line with Chirimbu and Tafazoli (2013) who believe, for many language learners around the world, new digital environments create a useful way for learning language and also the main medium in which they will actual use their second language in ever day life. Bicknell (1999) stated that using the Internet and its applications act as a motivational apparatus which gives students the chance to use all four language skills.

\section{CONCLUSIONS}

This study was an attempt to investigate the contributory role of virtual courses via Skype to control embarrassment of Iranian EFL learners. Presenting lecture through online programs such as Skype, in the form of virtual courses can be appropriate for EFL learners in technology era and education can witness a change from traditional to an online virtual mode. Although uses of software programs such as Skype have been widely used personally, there has been limited use on educational environment and for the employment in university classes.

Communication tools such as Skype could enable both students and teachers economize time and give them possibilities to manage the shortcoming in normal situations. From Psychological perspective, there is no problem for some students to present their lecture and have a face to face presentation, but for others with fragile personality and suffering from their embarrassment, it is such a big deal and Skype usage could be a presenting platform for these students and a remedy for such a problem. By having virtual courses and integration of technology, students can benefit from its advantages.

Despite its benefits to teachers, learners, and educational environment due to its immersion, it has some drawbacks such as developed property to conduct virtual courses and limitation of the Internet connection in Iran, but disadvantages related to Skype usage are minimal in comparison to the benefits. The findings of this study could be beneficial for policy makers and syllabus designers to include web-based activities, especially technology integrated presentations for the students to control their psychological barriers which hinder them from comfortable presentations. It could also have an application for the practitioners in the field by introducing applications such as Skype to assess their students' performance and presentations. The students' positive attitudes towards such applications could be used as an advantage to integrate technology in the classrooms. However, this study, similar to any other study needs further investigation to generalize it in different situations to confirm the findings. 


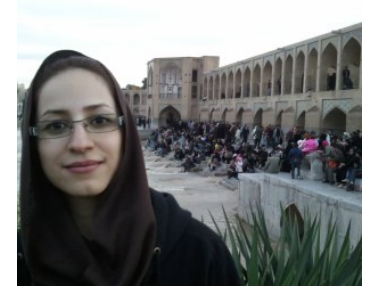

Elham JAHANBAKHSH was born in Isfahan, Iran in 1984. She received her MA degree in TEFL at English Department, IAU, Isfahan Branch, Iran in 2016. Her research interests are Computer-Meditated Communication (CMC), intercultural communication and Sociolinguistics. Using Technology and integration of it into pedagogical purposes in order to enhance teaching and learning particularly communication is one of her goal in her research papers. In addition, she is working on numerous articles in these areas.

Elham JAHANBAKHSH

English Department, Islamic Azad University, Isfahan Branch, Isfahan, Iran

Phone: +98 09131105951

E mail: e.nateghpoor@yahoo.com

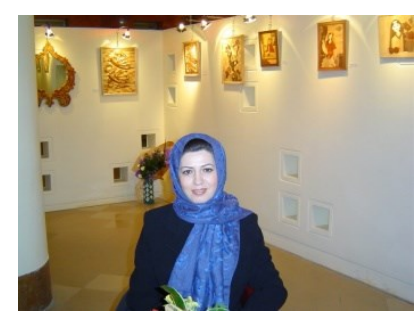

Azizeh CHALAK is an assistant professor of TEFL at the English Department of Islamic Azad University, Isfahan Branch, Isfahan, Iran. She has more than $\mathbf{2 0}$ years of experience in teaching English at graduate and undergraduate programmes in face-to-face and virtual English campuses. She is the managing editor of Research in English Language Pedagogy (RELP) published at IAU, Isfahan Branch and was selected as the top researcher of English Department in 2017. She has presented and published many papers at different conferences and journals both at international and national levels, and has been the reviewer of different journals or research projects. Her research interests include discourse analysis, sociolinguistics, intercultural communication, e-mail communications, computer-mediated communication (CMC), genre studies, and integration of technology in teaching.

\section{Dr. Azizeh CHALAK}

Managing Editor, Research in English Language Pedagogy (RELP)

English Department, Islamic Azad University, Isfahan Branch, Isfahan, Iran

Phone: +98-9122795543

E-mail: azichalak@gmail.com

\section{REFERENCES}

Asoodar, M., Marandi, S., Atai, M.R., \& Vaezi, Sh. (2014). Learner reflections in virtual vs. blended EAP classes. Computers in Human Behavior. Retrieved from www.elsevier.com/locate/comphumbeh

Atai, M. R., \& Dashtestani, R. (2013). Iranian EAP stakeholders' attitudes towards using the Internet in EAP courses for civil engineering students: Promises and challenges. Computer Assisted Language Learning, 26(1), 21-38.

Bicknell, J. (1999). Promoting writing and computer literacy skills through student authored webpages. TESOL Journal, 8(1), 20-26.

Bonk, C. J. (2011). The world is open: How web technology is revolutionizing education. USA: Jossey-Bass.

Brown, H. D. (2007). Teaching by principles: An interactive approach to language pedagogy (3rd Ed.). Englewood Cliffs, NJ: Prentice Hall Regents. 
Chirimbu, S., Tafazoli, D. (2013). Technology \& media: Applications in language classroom (TEFL, TESL \& TESOL). Professional Communication and Translation Studies, 6(1-2).

Dilamghani, M. (2001). Challenges and the necessary for virtual universities. National Development for Plan Virtual Universities. Retrieved from http://www.Itiran/ Article.com ORULP:http/VUaictc.com /docs/books/others/challenges.PDF

Elia, A. (2006). Language learning in tandem via Skype. The Reading Matrix, 6(3), 269-280.

Ely, C. (1986). An analysis of discomfort, risk-taking, sociability, and motivation in the L2 classroom. Language Learning 36(1), 1-25.

Fischer, K. W., \& Tangney, J. P. (1995). Self-conscious emotions and the affect revolution: Framework and overview. In J. P. Tangney \& K. W. Fischer (Eds.), Self-conscious emotions: The psychology of shame, guilt, embarrassment, and pride (pp. 3-24). New York: Guilford.

Fooladvand, M. \& Yarmohammadian, M.H. (2011). A comparative study between virtual and traditional approaches in higher education in Iran. Social and Behavioral Sciences, 28.

Levy, M. (2009). Technologies in use for second language learning. The Modern Language Journal, 93, 769-782.

Phillips, E.M. (1991). Anxiety and Oral Competence: classroom dilemma. The French Review 65(1), 114.

Richards, J. C., \& Renandya, W. A. (Eds.). (2002). Methodology in language teaching: An anthology of current practice. Cambridge University Press.

SteinbergF, S., \& Horwitz,E . K. (1986). The effect of induced anxiety on the denotative and interpretive content of second languages speech. TESOL Quarterly, 20, 131-136.

Tracy, J. L., \& Robins, R.W. (2003). Putting the self into self-conscious emotions: A theoretical model. Psychological Inquiry, 15, 103-135. 